\title{
Cross section structure influence to deformation of construction at accidental impacts
}

\author{
Vitaly Kolchunov ${ }^{1}$, Natalia Androsova ${ }^{2}$ and Sergey Savin ${ }^{1 *}$ \\ ${ }^{1}$ Southwest State University, 50 Let Oktyabrya str., 305040 Kursk, 94, Russia \\ ${ }^{2}$ Orel State University named after I.S. Turgenev, Komsomolskaya str., 302026 Orel, 95, Russia
}

\begin{abstract}
In this paper, results of numerical investigations of prefabricated RC structural systems, in particular influence to deformation at sudden bearing element removal it cross section, node links, reinforcement scheme and prestressing, are presented. It is shown, that it is possible to increase structural safety varying these parameters. Structural decisions of prefabricated elements, its nodes, recommendations for prestressing, which provide resistance against progressive collapse, are proposed.
\end{abstract}

\section{Introduction}

For majority of operated buildings, the resistance to load action at accidental interruption of technological processes, mechanical removal of supports, usually were not took in to account at designing, since it is accidental impacts and requires expensive constructive designs. However currently such impacts occur more often. Therefore, new generation of building codes [1-5] contain requirements, taking into account these accidental impacts to reach structural safety of buildings and save people's lives. At the same time solving of this problem linked not only with determination and rationing of such impacts but also investigation force resistance and destruction features. Therefore, investigation of stressstrain state at conditions above ultimate state of structures and cross section strength criteria development for such accidental impacts and linked with it structural transformation is actual scientific problem.

At last two decades in the world it was carried out a row of the investigations in field of defense of bearing structures against progressive collapse, development of computational models for accidental impacts [6-13], and generalization RC ultimate states theory to survivability problems [14-16]. In accordance with building codes and another building rules the safety of building and structures have technical, scientific and legal aspects. As it is noted in the paper [15] to solve these problems it is required additional investigations to develop methods for defense building and structures against progressive collapse. As variant, it is proposed dividing of building and structures to classes in accordance with it social significance and responsibility level [16]. Investigation results [10, 17-19] show that

\footnotetext{
* Corresponding author: suwin@yandex.ru
} 
sudden failure of structural system element leads to not only structural transformation of system but also dynamic force increasing into not destructured elements and cracking in RC structures, that also leads to additional dynamic forces $[18,19]$. However, as it was shown by calculations of real objects, this problem is difficult even in static staging by using computational models of first and second levels [20-22] and depends on the engineer qualification. And results of such calculation are difficult to interpret. Wherein for design engineer the final results of such calculation is evaluation of structure cross section or node behavior at states above it ultimate state for each structural element and it should include take into account cracking and another deformation features.

In accordance with it the one of the actual problem is investigation of stress-strain state features of bearing structural elements at states above ultimate state, taking into account dynamical force increasing and cracking. In particular, the one of such problems is determining of relationships for change of dynamic forces into reinforcement of RC statically indeterminate elements at cracking and structural transformation. Wherein it is practically significant to investigate behavior of mass RC frames of building and structures.

\section{Methods}

\subsection{Constructions of prefabricated RC frame of building}

The main advantage of the prefabricated RC structures technology is possibility to realize different architectural and planning solutions at high speed of building, using constructions produced by RC plants, for example as it is shown in fig. $1(a, b)$.

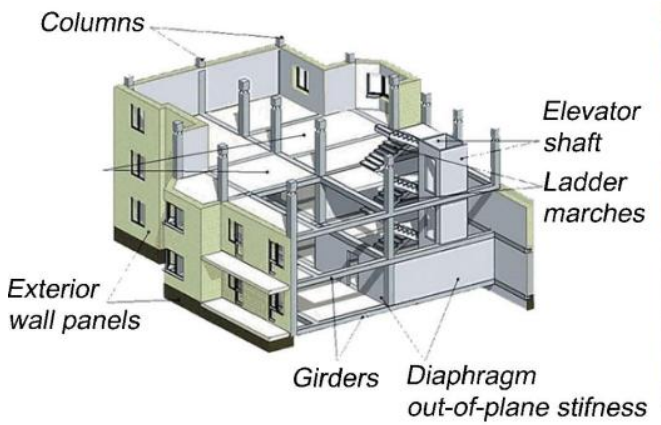

(a)

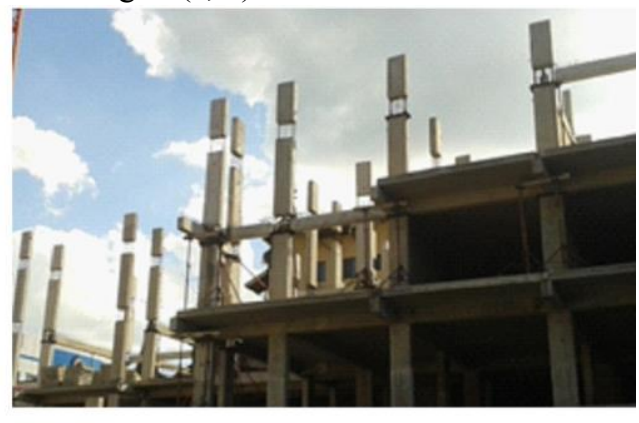

(b)

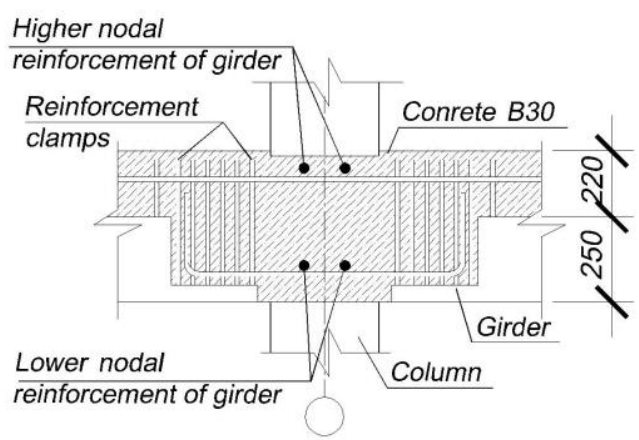

(c)

Fig. 1. Fragment of the prefabricated-monolithic structural frame of the building (a), general view of the prefabricated-monolithic structural system of 18-storey building in Kursk (b), node "girder column" (c) 
The basis of prefabrication technology is using of bearing structural frame including the following elements: columns, girders with or without prestressing of reinforcement, hollow-core overlap slabs or slab-formworks. The node "column - girder - slab" is monolithic. The elements of structural system are connected without welding at building. However, it should be taking into account some features of such structural systems at calculation and designing. In usual practice the designing of prefabricated-monolithic structure is analogous to designing of monolithic or entirely prefabricated structures and all calculations are carried out initially for prefabricated cross section height and after for entire cross section as it is shown in fig. 1 (c). The specific requirement to prefabricatedmonolithic structures is providing of contact node strength, that is why it is necessary to carry out calculation of nodal strength at designing.

In known construction designs [23], the prefabricated RC columns is fabricated from heavy C30 concrete and may have cross section from $200 \times 200 \mathrm{~mm}$ to $400 \times 600 \mathrm{~mm}$. Column reinforcement is carried out by bars of A400 by GOST 5781-82* or A500 by GOST R 52544-2006. The columns are fabricated as multi-level. In nodes "girder - slab" it is envisaged areas with bare reinforcement, which is reinforced by additional bent reinforcement bars. Connection of columns along it length is carried out by introduction of reinforcement bars of top part of column to the bottom and channels are filled by mortar.

Girders may have prestressing or can be fabricated without it. Prefabricated and prestressed girders is fabricated from heavy $\mathrm{C} 30$ concrete and reinforced by cables $\mathrm{K} 7$ of $12 \mathrm{~mm}$ diameter (GOST 3840-68*). The girders without prestressing are reinforced by bars A400 (GOST 5781-82*) or A500C (GOST R 52544-2006). Transverse reinforcement is applied in the form of closed clamp made of A400 by GOST 5781-82*. Bared closed clamps are constructively installed at top zone of girders, that in addition with reinforcement connectors provides connection of girder and slabs. After node "girder slab" monolithing the $\mathrm{T}$ - section appears. Wherein the prefabricated part of girder is wall of T-section and monolithed part of slab is shelf of it. The end section of prefabricated part of girder contains grooves for reinforcement bars, which link girder with column, and filled by fine-grained concrete.

\subsection{Computational models of deformation and destruction of RC frames of buildings}

Modeling of RC structural systems of building and structures at accidental impacts in the general case linked with analysis it deformation and destruction using 3D computational model and taking in account dynamics, physical and geometrical nonlinearity $[10,18,20]$. Creation of such model for entire structural system with necessary detailing at different analysis stages is hard, gives large data massive, which is difficult to interpret, and not always is effective in designing practice. Therefore, one of the possible algorithms to modelling destruction of structural system at accidental impacts may be algorithm based on the using of multi-stage computational models at quasistatic static formulation of problem and different requirement to computational results by each stage of analysis.

At the first stage the first level on the basis of computational model, which is shown in fig. 2, carried out calculation at acting loadings, using computer program, for example LiraSAPR, the result of which is information about the stress-strain state of all structural elements. Calculation is carried out at operating values of loadings (basic combination) and values of load reliability factor equals to 1 [2]. 


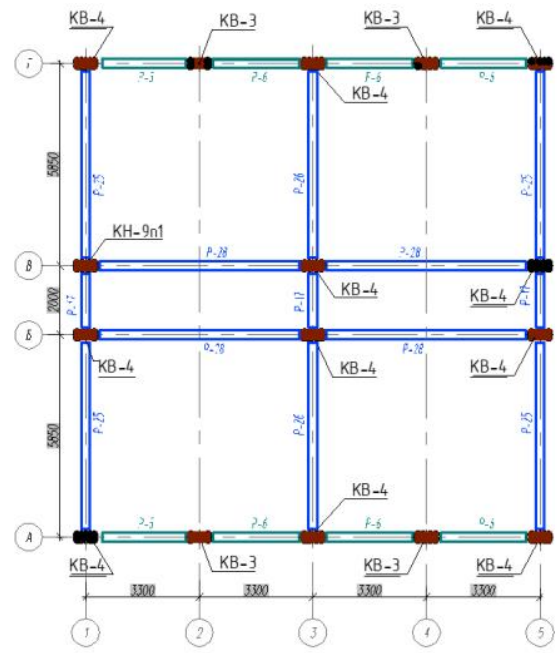

(a)

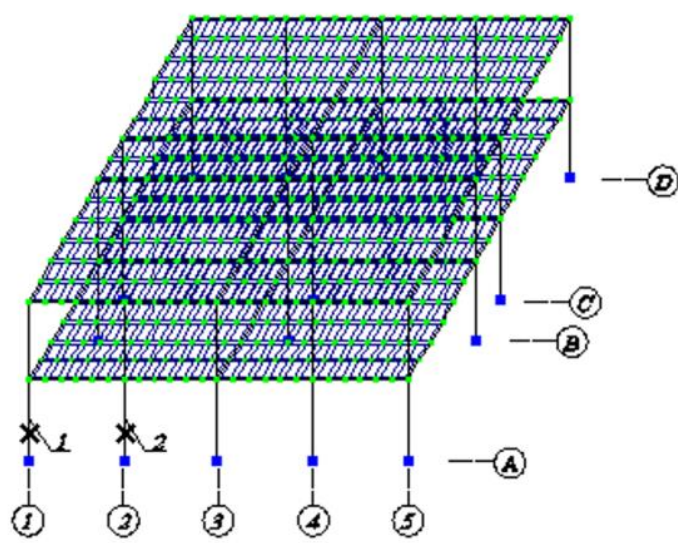

(b)

Fig. 2. Situation scheme for fragment of RC prefabricated-monolithic structural system (a), computational model for fragment of this structural system built in Lira-SAPR program (b), where $\mathrm{KB}$ - column, $\mathrm{P}$ - girder.

The result of stress-strain state analysis at basic loadings combinations is proposals to creating second level computational models to resistance assessment against progressive collapse at sudden removal one of vertical or horizontal bearing structural elements. Wherein the calculation against progressive collapse is carried out for each second level computational model without taking in account computational results obtained for another models.

\section{Results and discussion}

\subsection{Calculation of structural system resistance against progressive collapse}

For example, let us to calculate resistance against progressive collapse of the prefabricatedmonolithic structural system fragment with distance between columns equals $6 \times 6 \mathrm{~m}$.

The calculation is carried out in Lira-SAPR by second level computational models, in which corner column 1 and last row column 2 are removal respectively (fig. 2). Internal forces in removal column, obtained by first level computational model, act in opposite direction in second level computational model.

Physical nonlinearity is taking into account by using discrete-linear relationships for material deformation.

As criterion of especial ultimate state of RC structures it is proposed to use the following:

- restriction of compressed concrete deformation by ultimate value $E_{b 2}=0.0035$, which is determined from bilinear diagram of static and dynamic deformation and stresses values equal to $\varphi \cdot R_{b, s e r}$, where $\varphi$ is coefficient of dynamic strength increasing,

- restriction of tensiled steel reinforcement deformation by ultimate value $E_{s 2}=0.025$.

Character of deflections and crack width in RC structural elements at calculating by second level computational model with removal of the corner column 1 is shown in fig. 3 . 


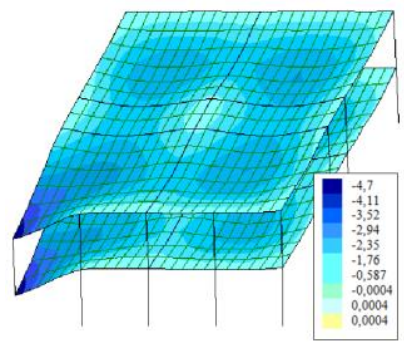

(a)

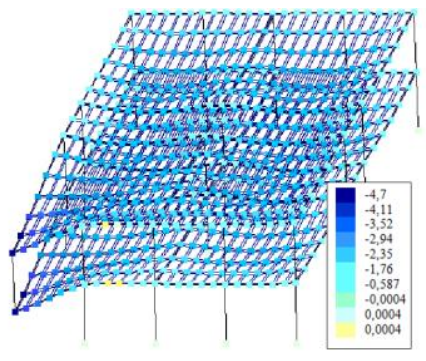

(b)

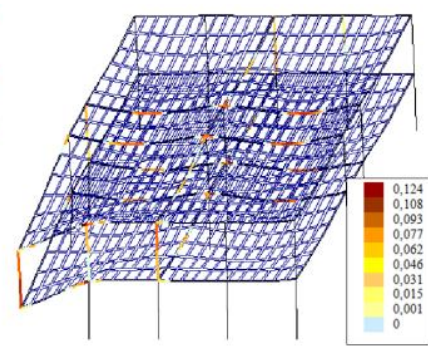

(c)

Fig.3. Deflection mosaic (mm) for overlap disk (a) and girder (b), cracks width (mm) in structural elements at sudden corner column removal (c)

The computational results show, that there is not local destruction. These data analysis shows that constructive design of RC prefabricated-monolithic structural frame excepts progressive collapse of entire framework at reviewed accidental impact.

\subsection{Evaluation of dynamic force increment into tensiled zone of $\mathrm{RC}$ elements at cracking after accidental impact}

The approach, using in some articles, for example [5, 11, 20], and computational programs (Lira-SAPR, SCAD) and linked with introduction of dynamic coefficient to loading, that is acting at each element of the system, is not correspond to physical meaning of the phenomenon. Here it is should be applied the term of dynamic force increment into not destructured elements of statically indeterminate system at sudden removal of it bearing element or section at cracking and decreasing of static indeterminacy level instead the term of dynamic coefficient to loading. As physical model of RC section force resistance it is taken the deformation model by V.M. Bondarenko and Vl.I. Kolchunov [24] to evaluate dynamic forces increment into tensiled cross section zone of RC bended element at accidental impacts. This model allows to take into account stress-strain state of crack area on the basis of fracture mechanics and $\mathrm{RC}$ mechanics constants more accurately.

The main point of such method is two-cantilever element appliance as computational model of cross section, that allows to link potential energy of deformed element with flexible constant $\xi$ of crack "coast" at its appearing, and link $\xi$ with traditional parameters of RC deformation, such as $E, G, \varepsilon$. In accordance with this model the internal forces scheme into RC cross section after cracking is presented in fig. 4 (a).

Longitudinal stresses distribution in tensiled concrete at some distance from crack is taken as equal-variable along the height of tensiled zone and sign-alternating near the crack. In the zone near reinforcement bar to the height of $t_{b}$ the tensile stresses change it direction at taking into account discontinuity effect [24].

For scheme of stresses distribution in tensiled concrete of bended element, accepted in fig. 4 , in accordance with $[8,16]$ the analytical relationship for dynamic forces into tensiled reinforcement bar takes the following form:

$$
N_{s}^{d}=N_{s}+N_{b t}
$$

where $N_{s}$ is internal tensiling force in reinforcement, caused by eternal load $P ; N_{b t}$ is internal force in tensiled concrete. 


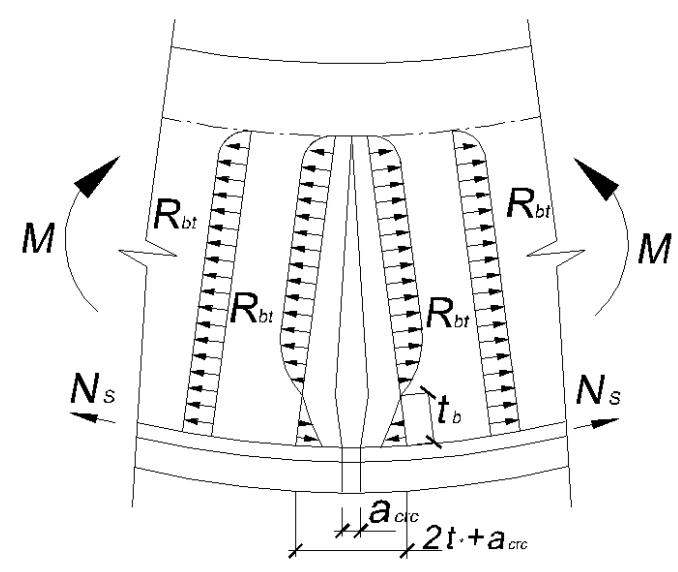

(a)

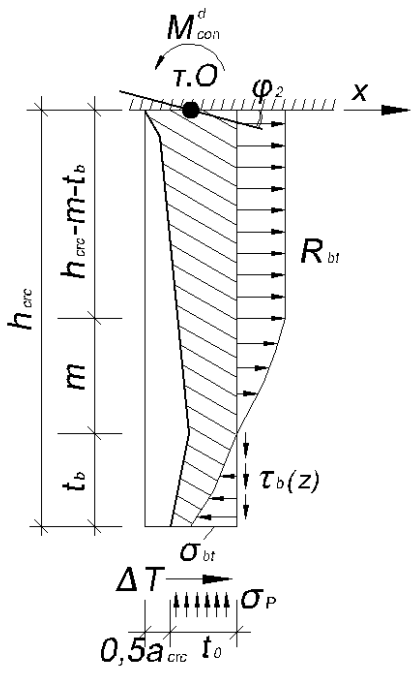

(b)

Fig. 4. Scheme for calculation of dynamic force increment into RC bended element: section at crack formation moment (a), two-cantilever element model (b)

The resultant forces into tensiled concrete $N_{b t}$ near the crack "coasts" are determined on the basis two-cantilever model [24]. For reviewed RC bended element at crack formation moment it takes the following form (fig. 4 (b)):

$$
N_{b t}=-\Delta T+0.5 \cdot \sigma_{b t} \cdot b \cdot t-R_{b t} \cdot b \cdot\left(h_{c r c}-t-m\right)-2 \cdot R_{b t} \cdot m / 3,
$$

where $b$ is width of RC cross section; $t=1.5 d$ is parameter, which characterizes height of compressed zone above the crack (here $d$ is reinforcement diameter); $h_{c r c}$ is crack length; $x_{c r c}$ is height of compressed concrete into section at crack formation moment; $\Delta T$ is shear force, acting through contact zone between concrete and reinforcement; $m$ is height of predestruction zone.

Tangential and normal stresses into reinforcement $\tau_{b}(z)$ and $\sigma_{p}$, which are presented in two-cantilever model in fig. 4 (a), are not included into equilibrium equations since it projections to $x$ axis equal to zero, and into moment equilibrium equation it leverages are too small. Nail effect in reinforcement is not taken into account.

Proposed analytical relationships for dynamic force increment into reinforcement of bended RC element at cracking are tested by calculation of prefabricated-monolithic prestressed RC girder. The girder of $5.55 \mathrm{~m}$ length designed as prefabricated-monolithic from $\mathrm{C} 30$ concrete with cross section height equal $600 \mathrm{~mm}$ and with prestressed cables $\mathrm{K}-7$ of $12 \mathrm{~mm}$ diameter ( 6 cables with area $A_{s}=5.58 * 10^{-4} \mathrm{~m}^{2}$ ) as cross section reinforcement.

As calculation result by formula (2) it is obtained internal force into tensiled concrete $N_{b t}=1.314 \mathrm{kN}$. Calculation is carried out at moment of cracking $M_{c r c}=399.76 \mathrm{kN} \mathrm{m}$.

The internal force into tensiled reinforcement of the girder is $N_{s}=676.33 \mathrm{kN}$.

Value of dynamic force into reinforcement of girder is $N_{s}^{d}=702.95 \mathrm{kN}$.

Respectively, coefficient of dynamic force increment at crack formation is $\theta=N_{s}^{d} / N_{s}$ $=1.039$.

Crack formation leads also to increment of stresses $\left(\Delta \sigma_{s p}^{d}=125.977 \mathrm{MPa}\right)$ in reinforcement at cross section with crack. This phenomenon becomes especially danger for prestressed structures, the reinforcement of which has high level of stresses before 
additional dynamic force increment. For reviewed girder it is $\sigma_{s p}=1240 \mathrm{MPa}$. Respectively, at moment of dynamic force increment caused by accidental impact the stress into prestressed reinforcement equals: $1240+125.977=1365.77 \mathrm{MPa}<R_{s, n}=1475 \mathrm{MPa}$.

\section{Conclusions}

$\mathrm{RC}$ structural system of reviewed building is designed by frame-bracing scheme. Appliance of such structural system for buildings with high and normal responsibility level requires additional constructive designs to provide resistance against progressive collapse.

At protection designing for RC structural system of reviewed building it is necessary to take into account in second level computational model (after an element removal) the coefficient of dynamic force increment. For more accurate evaluation these increments in $\mathrm{RC}$ structures it is proposed to take into account strain-stress state near the crack at it formation.

\section{References}

1. Federal law of RF No $384 \mathrm{FZ}$ from 30.12.2009 "Technical regulation of structural safety of buildings and structures".

2. Building Code SP 296.1325800.2017 "Building and Structures. Accidental impacts" (2017)

3. State Standard of RF GOST 27751-2014 "Reliability of structures and foundations. Main provisions" (2015)

4. UFC 4-023-03 (Including Change 3, 2016) Unified facilities criteria. Design of buildings to resist progressive collapse.

5. EN 1992-1-1-2009 Eurocode 2: Design of concrete structures - Part 1-1.

6. S.A. Zenin, R.S. Sharipov, O.V. Kudinov, G.I. Shapiro and A.A. Gasanov, ACADEMIA. Architecture and construction, 2, 7 (2016)

7. V.I. Travush, V.N. Ponomarev, V.M. Bondarenko, K.I. Eremin, Architecture. Construction. Education, 4, 109 (2014)

8. V. Travush, S. Emelianov, V. Kolchunov, A. Bulgakov, Procedia engineering, 164, 416 (2016)

9. V.I. Travush, N.V. Fedorova, Russian J. of Building and Architecture, 1, 6 (2017)

10. V.I. Kolchunov, N.V. Klyueva, N.B. Androsova, A.S. Bukhtiyarova, Survivability of buildings and structures at accidental impacts (Publishing ASV, Moscow, 2014)

11. Fengwei Shi, Lai Wang, Shuo Dong, The Open construction and building technology J., 11, 200 (2017)

12. Min (Max) Liu, Akbar Pirmoz, Engineering structures, 123, 372, (2016)

13. B. A. Izzudin, A. G. Vlassis, A. Y. Elghazouli, D. A. Nethercot, Engineering structures, 30, 1308 (2008)

14. N.V. Fedorova, P.A. Korenkov, Stroitelstvo i rekonstruktsiya, 67, 60 (2016)

15. V.I. Travush, Y.S. Volkov, Standards and quality, 1, 62 (2016)

16. E.N. Kodysh, N.N. Trekin, D.A. Chesnokov, Promyshlennoe i grazhdanskoe stroitelstvo, 6, 8 (2016)

17. V.I. Kolchunov, S.G. Emelianov, Zhilishchnoe stroitelstvo, 10, 17 (2016) 
18. V.I. Kolchunov, N.B. Androsova, Scientific Herald of the Voronezh State University of Architecture and Civil Engineering Construction and Architecture, 4, 6 (2016)

19. N.V. Fedorova, T.A. Khalina, Promyshlennoe i grazhdanskoe stroitelstvo, 5, 32 (2017)

20. G.I. Shapiro, A.A. Gasanov, International J. for Computational Civil and Structural Engineering, 12, 158 (2016)

21. N.V. Klyueva, N.B. Androsova, Stroitelstvo i rekonstruktsiya, 4, 72 (2015)

22. V.I. Kolchunov, N.V. Fedorova, Vestnik NIC Stroitelstvo, 1, 115 (2015)

23. Patent of RF RUS 97405 20.01.2010. Prafabricated-monolithic reinforced concrete structural system of buildings (2010)

24. V.M. Bondarenko, V1.I. Kolchunov, Computational models of force resistance of reinforced concrete (Publishing ASV, Moscow, 2004) 